\title{
A time of transition: changes in Irish food behaviour and potential implications due to the COVID-19 pandemic
}

\author{
M. Henchion ${ }^{1 \dagger}$, S.N. McCarthy ${ }^{1}$ and M. McCarthy ${ }^{2}$ \\ ${ }^{1}$ Teagasc Research Centre, Ashtown, Dublin 15, Ireland \\ ${ }^{2}$ Dept of Marketing, Cork University Business School, University College Cork, Ireland
}

Abstract

Consumers' food choice decisions are generally relatively stable over time; consumers engage in habitual decisionmaking due to the high frequency of such decisions for efficiency reasons. As a result, habits are strong predictors of eating behaviour. However, changes in the life of the individual or the external environment can result in more conscious consideration of food choice motives and a transition to new patterns of behaviour to fit the new context. The coronavirus disease 2019 (COVID-19) pandemic is examined in this paper as a particularly useful case of how a change in context affects food choice trajectories. Drawing on results from an online survey of 651 food consumers in Ireland, it examines food planning, shopping, preparation and eating behaviour, including stockpiling and influences on decision-making. Overall, it finds significant evidence of a transition towards new patterns of behaviours, with two distinct clusters identified - the "Covid copers" and the "restless restrictors". For both groups, the shopping experience has become stressful resulting in reduced frequency of shopping and higher levels of planning. Conversely, time pressures related to cooking have reduced, with enjoyment associated with such activities. This is also reflected in stockpiling behaviour; the top three foods most likely to have been stockpiled in Ireland were pasta/rice, eggs and flour, reflecting the nation's desire to bake and cook during the pandemic. These behaviours are discussed in the context of emerging supply chain actor responses, with considerations for future strategic decisions identified, along with some opportunities for public health nutrition interventions.

Keywords

Consumer behaviour $\cdot$ COVID-19 $\bullet$ food behaviour transitions $\bullet$ food choice $\bullet$ lockdown

\section{Introduction}

Consumer food choice decisions occur frequently, are multifaceted, situational and represent a complex interplay of many and varied influences that have shaped and framed food beliefs and behaviours. These decisions relate to all aspects of the food consumption process, from acquisition through to waste disposal. According to Devine et al. (1998), due to the high frequency of food decisions, a food choice trajectory emerges which represents a pattern of "persistent thoughts, feelings and actions" around food practices, over time. This trajectory affords the person (shopper/consumer) efficiencies in their food decisions, while ensuring their food motives are fulfilled. Thus, behaviour becomes habitual with many decisions made with minimal effort, such that, as indicated by prior research, habits are strong predictors of eating behaviour (van't Riet et al., 2011). Indeed, these habits and routines play such a significant role in the everyday food practices of most individuals and households that they distract from the use of deliberative decision-making.
Verplanken \& Aarts (1999) defined such habits as "learned sequences of acts that have become automatic responses to specific cues, and are functional in obtaining certain goals or end states". This highlights two important points: (1) habits are effective in reducing effort (cognitive and time) in making food-related decisions, and (2) habits are in their origin linked to goal attainment. Consequently, it is unlikely that a habit will change while the context within which it is practiced remains stable or unchanged. Indeed Verplanken \& Wood (2006) highlight that when designing strategies that seek to change embedded habits and routines one needs to disrupt the environmental cues that trigger the habitual response. Furthermore, changing these habits may be viewed as effortful by consumers due to deficits in relevant knowledge and skills (McCarthy et al., 2017). Fundamentally, habits and routines are generally nestled in a relatively stable environment and it is when this environment, or the life of the individual, changes new patterns that fit 
within the new context emerge. These new patterns may be temporary or may become embedded as new ways of thinking, feeling and doing food. Further, they can represent "teachable" moments as many of the subconscious everyday practices around food are consciously reflected upon. Consequently, many individuals seek out information on new ways of "doing" food, for example, shopping, cooking, eating and waste management. Normally, individuals do not make drastic consumption modifications as a result, but responses to changes can alter the direction of a trajectory. However, the nature of this direction change depends on existing perceptions, resources, ideals and, of course, personal characteristics of the individual. As a result, the same event can have differing impacts across a population.

The coronavirus disease 2019 (COVID-19) pandemic has presented a particularly useful case to consider how a change in context affects food choice trajectories. A dramatic change in the food-purchasing context, along with a range of restrictions on how we live our everyday lives, presented a set of challenges for the Irish population on all aspects of food acquisition, use and disposal. A shift to working from home, being furloughed or losing one's job, closing of restaurants and other foodservice outlets, queueing to gain access to food retail outlets, reduced brand options and the need to behave very differently while navigating the retail outlet, to name but a few of the changes, all impacted food-related decisions. Early findings on the impact of COVID-19 suggest that patterns have changed with examples such as increasing levels of snacking (Robinson et al., 2021), reductions in shopping frequency (Laguna et al., 2020) and changes in product choices (Laguna et al., 2020) reported.

The question that this paper seeks to explore is how this shared experience (COVID-19 pandemic and related restrictions during the first lockdown) translated into alterations in food choice trajectories amongst Irish consumers and the extent to which personal characteristics impact the level and direction of this alteration. Specifically, the aim of the present research was to examine changes in eating behaviour and food purchases during the first COVID-19 lockdown among Irish adults and to examine differences between groups of individuals. The paper proceeds by outlining the way COVID-19 restrictions unfolded in Ireland, outlining the methodology followed in undertaking a survey of 651 consumers in Ireland, and presenting the results of the survey according to shopping, planning, selecting and preparing foods, cooking skills and food choice influences. It concludes with a discussion about the implications of the results for various actors in the food supply chain and for public health nutrition (PHN).

\section{How the COVID-19 pandemic evolved in Ireland (January to March 2020)}

The first indication of an emerging problematic viral outbreak came when the Chinese authorities informed the World Health Organization (WHO) of pneumonia type cases from an unknown cause on the last day of 2019. Three days later, 44 more cases had presented as patients and within $1 \mathrm{wk}$ China had identified a new coronavirus as the cause of the outbreak. By the end of January, many cases had been confirmed across the world, with the first cases in Europe confirmed in France on 25 January 2020. While the significance and potency of this virus were recognised early, and in China lockdowns commenced in the last 2 wk of January, national governments responded differently to the threat.

In Ireland, media attention started to be given to the virus around the end of the second week of January at which point the government was already monitoring the situation. By the end of January (27 January), the National Public Health Emergency Team (NPHET) was established to oversee the national response to the emerging pandemic and advise the government accordingly. At the same time, the WHO had raised the risk of the spread of the virus from high to very high. The first case in the Republic of Ireland was confirmed at the end of February and within a week 17 further cases were confirmed. By the end of the second week of March, the WHO had elevated the status of the outbreak to a pandemic and indicated that Europe had become the epicentre of the pandemic. In Ireland, 90 cases had been confirmed; by this point the government had advised against travel to particular regions and had cancelled large gatherings such as St. Patrick's Day parades. On 12 March, the Taoiseach introduced the first restrictive measure; all schools, colleges, childcare facilities and cultural institutions were instructed to close until the end of the month, pubs were also asked to close and restrictions were imposed on the size of indoor and outdoor gatherings. Confirmed cases continued to grow leading to the issuing of a countrywide mandatory stay at home order (lockdown) for everyone, apart from certain exceptions, for a 2-wk period from 27 March to 12 April. This period was subsequently extended to 6 May. The lockdown involved citizens only leaving home to shop for food and other essential items, and to exercise briefly within $2 \mathrm{~km}$ of their homes. Travelling further than $2 \mathrm{~km}$ was only allowed in exceptional circumstances, that is, to and from work, where work was an essential service that could not be done from home, or to shop for essential food and household goods or for medical reasons. People over $70 \mathrm{yr}$ of age were asked to cocoon. All non-essential 
retail outlets were closed, and restaurants and diners were closed, with takeaways allowed to remain open. Some food service operations changed their business models to provide delivery services or order-and-collect options. Grocery outlets restricted the number of shoppers at any one time, provided hand sanitisers and gloves for shoppers, introduced dedicated hours for those in more vulnerable groups and prioritised such groups for delivery services. Many employees transitioned to working from home, whilst others were furloughed or made redundant.

\section{Materials and methods}

\section{Study design and recruitment}

Ireland participated in a cross-sectional online survey that was launched in 38 countries worldwide, between April and June 2020. This international online survey was coordinated by the University of Antwerp and received ethical approval from the Ethics Committee for the Social Sciences and Humanities of the University of Antwerp (approval code 20_46). A full overview of the study protocol and analysis of the international data has been previously published (De Backer et al., 2021). In summary, respondents were aged between 18 and $65 \mathrm{yr}$ and resided in the Republic of Ireland during the COVID-19 crisis. The software platform Qualtrics XM (Provo, UT USA) was used to host the survey and capture the data. Respondents were recruited through convenience sampling and snowballing techniques using social media, personal and professional networks. The survey was also promoted via a national press release. A total of 651 respondents completed the survey in Ireland.

\section{Survey statements and measures}

The survey instrument included measures and constructs relating to shopping, planning, selecting and preparing foods, cooking skills and food choice influences. Respondents were asked to respond to questions relating to each item twice, that is, reporting their behaviour before the COVID-19 crisis and at that moment (during COVID-19 restrictions/lockdown) on a Likert scale of 1 to 7 . In addition, demographic information on gender, age, educational attainment, employment status and household composition was collected.

In order to assess the impact of a pandemic on a population during lockdown restrictions, which were never before witnessed in living memory, psychological distress was measured using the Kessler K6 scale (Kessler et al., 2002). For this survey, respondents indicated on a seven-point frequency scale ( $1=$ never, $7=$ all the time) how often they experienced each of the six feelings, such as restlessness and nervousness, since the COVID-19 crisis.

\section{Statistical analysis}

Statistical analyses were performed using IBM SPSS Statistics for Windows, Version 24.0 Armonk, NY: IBM Corp. K-means cluster analysis was performed on the six statements from the Kessler K6 scale to identify if clusters of consumers could be generated and profiled based on psychological distress during lockdown. To determine the difference between two variables separated by time (before and after lockdown) for the same subject, paired $t$-tests were employed to test for significant changes in the mean scores across shopping, planning, selection and preparation of foods for the total sample and then within the clusters for before and during lockdown.

\section{Results}

The cluster analysis generated two meaningful clusters as presented in Table 1. The larger cluster with 400 respondents was more positive regarding statements of feeling more connected and having more time, and was less likely to experience negative emotions of depression, hopelessness, etc. This group, based on their positive emotions during lockdown, was labelled the "Covid copers". The second and smaller cluster had a lower sense of connection since lockdown while experiencing stronger emotions relating to restlessness, nervousness and everything requiring effort. This second group was labelled the "restless restrictors".

Table 2 presents the demographic profile for the total sample and for each of the two clusters, with comparisons to the total population as collected by the Central Statistics Office (CSO) census in 2016. A higher proportion of females, younger people and highly educated than in the population generally participated in the study. The mean age of the sample is

Table 1: Final cluster centres for the $K 6$ psychological distress statements

\begin{tabular}{lcc}
\hline Since lockdown, I feel.... & \multicolumn{2}{c}{ Cluster } \\
\cline { 2 - 3 } & $\mathbf{1}(\boldsymbol{n}=\mathbf{2 5 0})$ & $\mathbf{2}(\boldsymbol{n}=\mathbf{4 0 0})$ \\
\hline Hopeless & 3.62 & 1.61 \\
Restless or fidgety & 4.48 & 2.76 \\
That everything requires effort & 4.32 & 2.51 \\
Feel worthless & 3.02 & 1.32 \\
Feel nervous & 4.29 & 2.38 \\
So depressed that nothing could cheer me up & 2.64 & 1.22 \\
I have more time than usual & 3.83 & 4.11 \\
More connected than usual & 3.10 & 3.71 \\
\hline
\end{tabular}

Scores for Likert scale from 1 to 7 where $1=$ never, 4 = sometimes, $7=$ always. 
Table 2: Socio-demographic profile of the sample participants in the COVID shopping survey, across clusters and compared to the CSO census of 2016

\begin{tabular}{|c|c|c|c|c|c|}
\hline & $n$ & $\%$ & Restless restrictors (\%) & Covid copers (\%) & Census 2016 \\
\hline \multicolumn{6}{|l|}{ Gender } \\
\hline Female & 480 & 74 & 78 & 72 & 49 \\
\hline Male & 167 & 26 & 22 & 28 & 51 \\
\hline \multicolumn{6}{|l|}{ Age group (yr) } \\
\hline $18-24$ & 90 & 17 & 24 & 13 & 18 \\
\hline $25-44$ & 366 & 69 & 69 & 69 & 45 \\
\hline $45-65$ & 74 & 14 & 7 & 18 & 36 \\
\hline Average age (yr) & & 34.1 & 31.3 & 35.5 & 37 \\
\hline \multicolumn{6}{|l|}{ Education } \\
\hline Leaving certificate/PLC & 114 & 18 & 13 & 20 & 69 \\
\hline Degree & 122 & 19 & 20 & 18 & 20 \\
\hline Post-graduate & 262 & 40 & 43 & 39 & 10 \\
\hline Doctorate & 153 & 24 & 24 & 23 & 1 \\
\hline \multicolumn{6}{|c|}{ Employment status before lockdown (since lockdown) } \\
\hline Student & $33(35)$ & $5(5)$ & $7(8)$ & $4(4)$ & 11 \\
\hline Employed & $577(542)$ & $89(83)$ & $90(84)$ & $88(83)$ & 53 \\
\hline Not working & $41(74)$ & $6(12)$ & $3(8)$ & $8(13)$ & 35 \\
\hline
\end{tabular}

Values in brackets indicate value during the lockdown period.

COVID = coronavirus disease $;$ CSO = Central Statistics Office $;$ PLC = post-leaving certificate .

comparable to the total population. The higher proportion of women undertaking the grocery shopping in this study reflects findings of other Irish shopping surveys, whereby more than two-thirds of women undertake the weekly shopping duties for a household. ${ }^{1}$ The higher education level reflects the convenience sampling methods that used networks associated with the authors. The demographic distribution of the clusters was similar to that of the total population, although the restless restrictors had a higher proportion of females and in the younger age group.

Nearly $90 \%$ of respondents were employed before lockdown, which decreased to $83 \%$ during lockdown with a similar decrease for both the restless restrictors and Covid copers. Most of the respondents reported that they were working from home since lockdown. The composition of the household changed (people moved in or out) for $20 \%$ of respondents, $60 \%$ of respondents did not have any children in the household and $87 \%$ lived with at least one other adult (data not shown). Table 3 presents the "who, how and where" of shopping and retail behaviour before and during lockdown. Nearly $90 \%$ of respondents reported that they completed their shopping by themselves or with a partner before lockdown; this reduced to

${ }^{1}$ https://www.shelflife.ie/research-women-still-grocery-shopping-home/.
$83 \%$ during lockdown with a slight increase in others completing this task. There was a small but significant decrease in people physically going to the supermarket, corresponding to a small increase in click and collect and online deliveries. During lockdown, the supermarket continued to be the primary point of purchase with all other retail points experiencing a significant decrease, in particular farmers' markets. Similar trends were observed across the two clusters. There was limited evidence of stockpiling behaviour with no products from a pre-defined list of 23 products scoring 5 or more on a seven-point scale relating to purchase frequency (where $1=$ a lot less than usual, $4=$ no more or less and $7=$ a lot more than usual). Nonetheless, the top three foods most likely to have been stockpiled in Ireland, according to our respondents' self-reported behaviour, were pasta/rice, eggs and flour, with ready meals being the least likely (data not shown).

Our respondents indicated that good hygiene standards and safety norms were the most important aspects of shopping for them, significantly increasing in importance since lockdown as shown in Table 4. Enjoying the shopping atmosphere decreased significantly in importance from a positive rating before lockdown to a negative rating since restrictions were imposed. Similarly, considerations regarding price, food variety and environmental considerations decreased significantly in importance for the respondents over the two periods in 
Table 3: The "who, how and where" of shopping and food acquisition before and during lockdown restrictions

\begin{tabular}{|c|c|c|c|c|c|}
\hline & \multicolumn{2}{|c|}{ Before LD } & \multicolumn{2}{|c|}{ Since LD } & \\
\hline Who & $\%$ & & $\%$ & & \\
\hline Self & 59.8 & & 54.3 & & \\
\hline Self and other & 29.2 & & 28.4 & & \\
\hline \multirow[t]{3}{*}{ Partner or other } & 11.0 & & 17.3 & & \\
\hline & \multicolumn{5}{|c|}{ Total sample } \\
\hline & Mean & s.d. & Mean & s.d. & Significance \\
\hline How I shopped... ${ }^{1}$ & \multicolumn{2}{|c|}{$n=466$} & & & \\
\hline Went to the supermarket, shop & 6.58 & 0.85 & 6.18 & 1.56 & *** \\
\hline Ordered online, collect at a seller's point & 1.27 & 0.79 & 1.58 & 1.40 & *** \\
\hline Ordered food online, delivered at home & 1.50 & 1.17 & 1.72 & 1.57 & ** \\
\hline Where I shopped... ${ }^{1}$ & \multicolumn{2}{|c|}{$n=465$} & & & \\
\hline Supermarket & 6.27 & 0.81 & 6.22 & 1.12 & ns \\
\hline Corner store/convenience store & 3.61 & 1.50 & 3.33 & 1.76 & *** \\
\hline Organic/fairtrade food shop & 2.68 & 1.67 & 1.78 & 1.43 & *** \\
\hline From farmer/producer/farmers' market & 2.57 & 1.64 & 1.88 & 1.60 & *** \\
\hline Bakery, butcher, delicacy shop & 3.93 & 1.55 & 3.08 & 1.98 & *** \\
\hline Via box schemes & 1.16 & 0.68 & 1.22 & 0.93 & ns \\
\hline
\end{tabular}

17 point frequency scale ranging from $1=$ never, $4=$ sometimes to $7=$ every-time.

${ }^{* * *}=P<0.001,{ }^{* *}=P<0.01, \mathrm{~ns}=$ non-significant.

$\mathrm{LD}=$ lockdown.

question. They also reported that shopping had become more stressful for them as well as increasingly frustrating, with a significant increase in these scores reported for the during lockdown period. These changes were more notable in the restless restrictors group, who recorded greater changes in these measures when lockdown measures were introduced compared to previously.

Table 5 presents the impact of restrictions on meals, with changes observed in planning, preparation and dining. Consumers' reported use of planning behaviours, for example, making shopping lists and planning meals in advance of shopping, increased significantly during lockdown compared to before lockdown. An increase in confidence to cook and prepare healthier meals was also observed from respondentreported behaviour. Using leftovers as well as not throwing away foods increased during lockdown. An increase in positive meal behaviours during lockdown was also reported, whereby the meal became a more important aspect of daily lives, and respondents were less likely to eat in front of the television, while instead choosing to eat at the dining table.

As shown in Table 6 all respondents reported a high level of cooking skills before lockdown but they also reported that these skills increased during lockdown. The most notable increase is reported for baking bread. This suggests that respondents gave more time and attention to cooking and baking. Cooking was also reported to be significantly less frustrating and less stressful, and less time-consuming for all. These changes were most notable in the restless restrictors cluster. When it came to recipes and cooking meals, having the ingredients at home became significantly more important as did the comforting aspect of food. Time required to prepare a meal became significantly less important while there was no change in environmental considerations. Many of these changes were more notable in the restless restrictors cluster.

\section{Discussion}

This research provides evidence of changes in consumer food-related behaviour from planning, through to shopping, preparing and eating during COVID-19 restrictions in Ireland, that is, consumers made decisions so that their behaviour adapted to fit the new context. It has also identified how different clusters of consumers respond differently to the distress of a pandemic in their behaviours. As a pattern of increasing and decreasing restrictions becomes apparent across Europe in response to the dynamics of the COVID-19 pandemic, it is important to understand what behavioural changes are evident, the drivers of such changes, differences between consumer groups and the implications of such changes. 


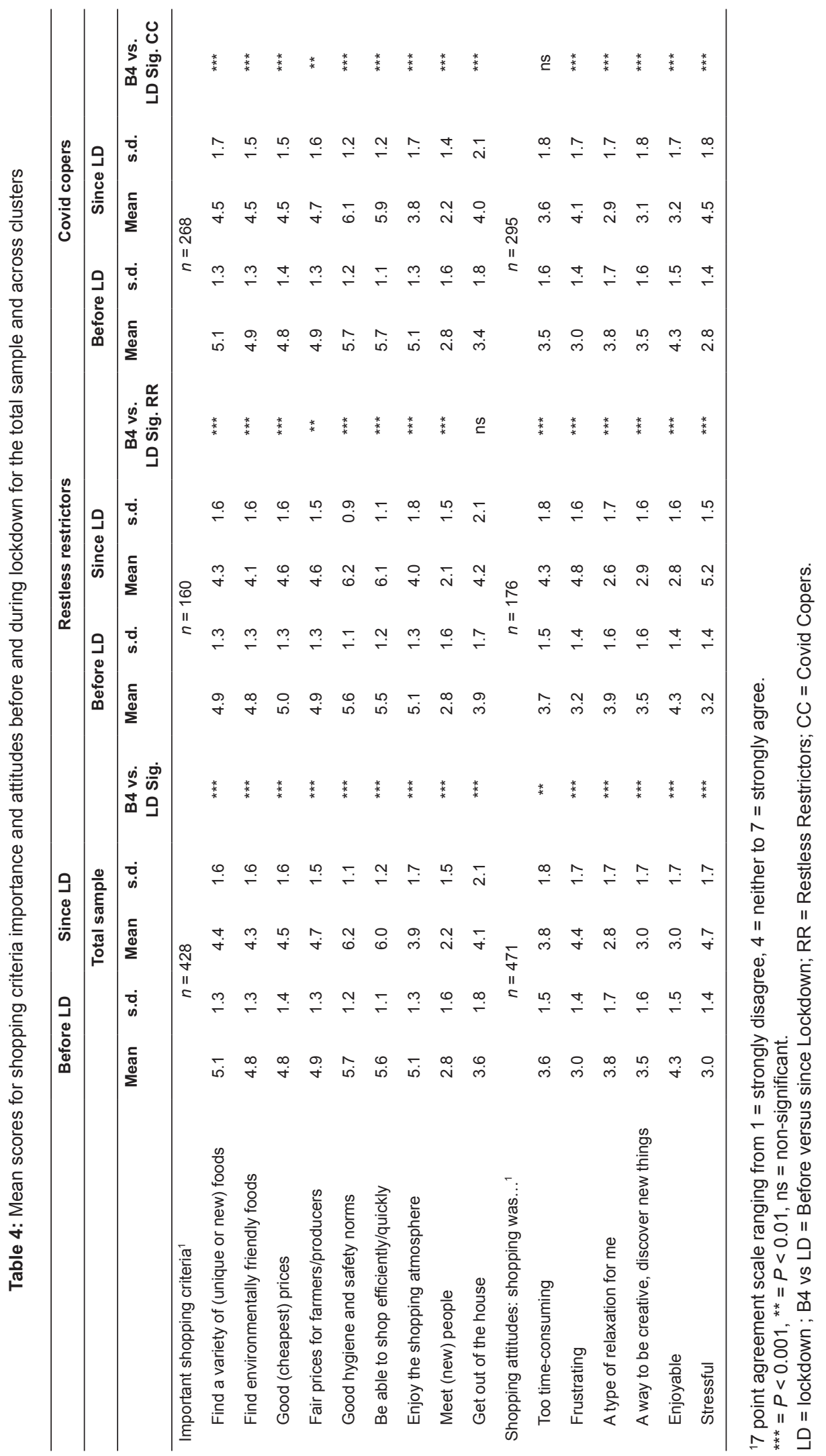




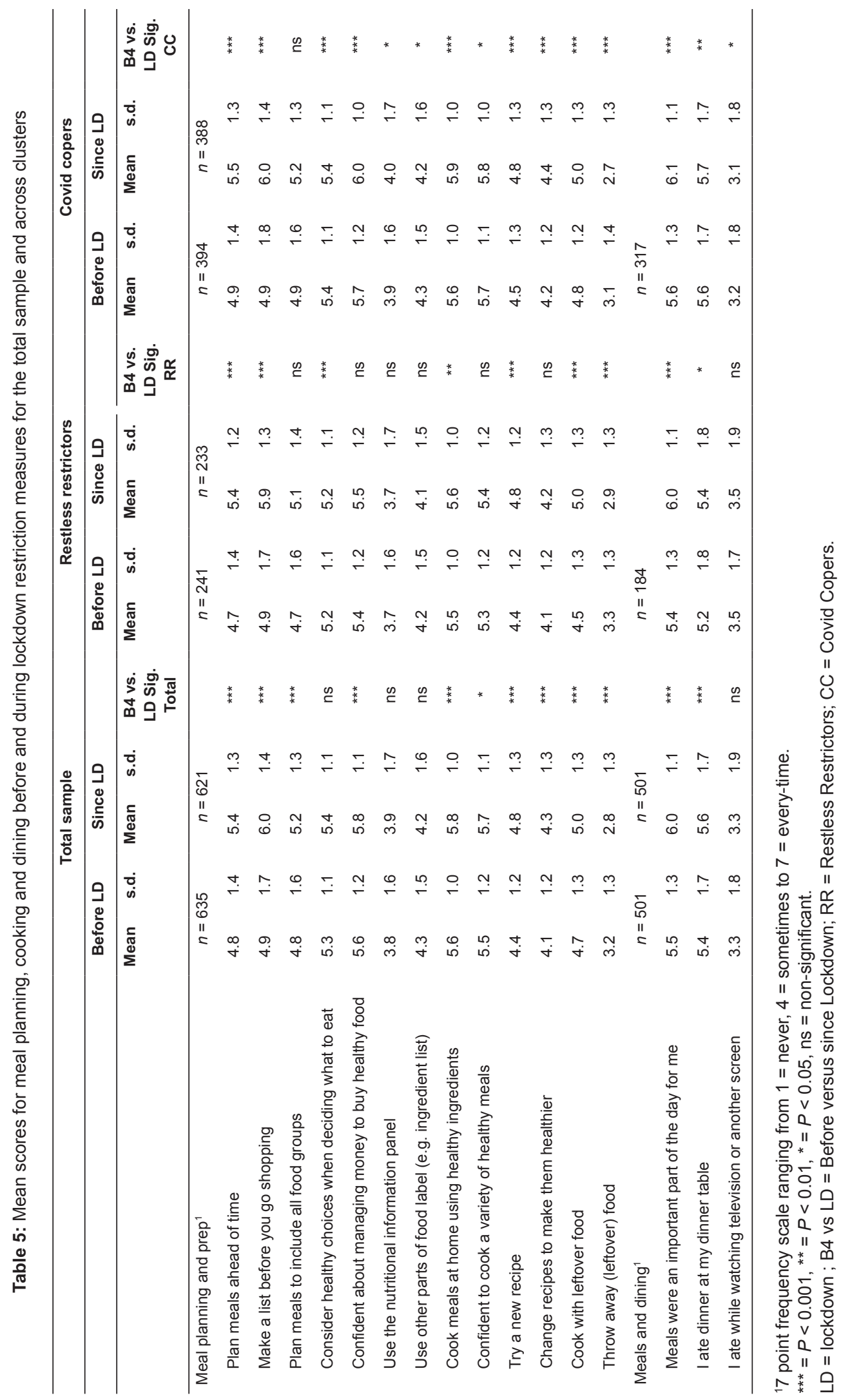




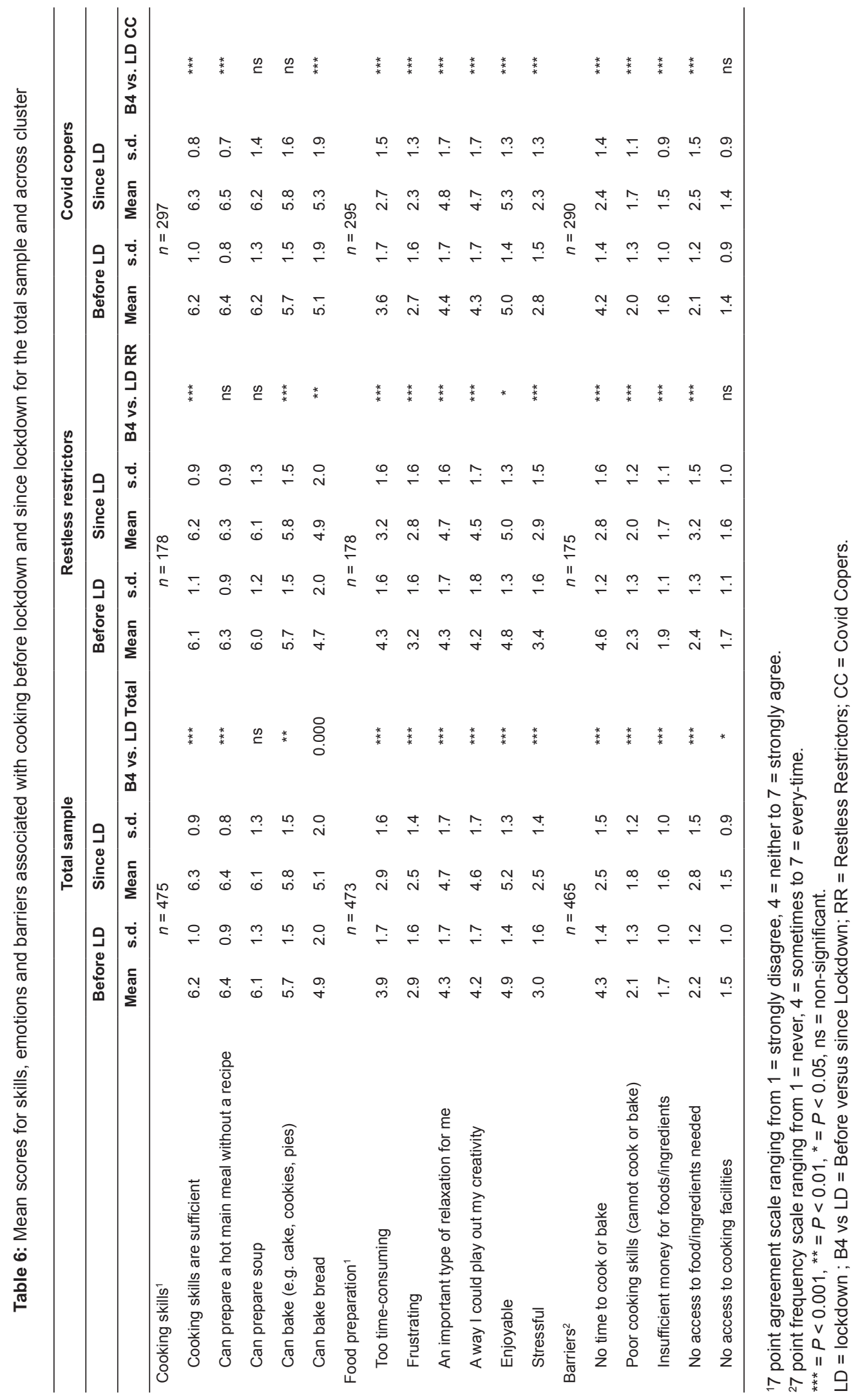


The research provides evidence of consumers feeling that they faced additional stress, as a logical psychological response to a pandemic, and a desire to maintain some control over their everyday life practices. Furthermore, it shows this translating into changes in a broad range of food behaviours. Similar to Becdach et al.'s (2020) observation on the impact of changing "rules" and emerging social norms around in-store food shopping (controls on the number of people in a shop at any one time, the need to get through the shop quickly and the need to behave in new ways while shopping), COVID-19 restrictions reduced the hedonic aspects of the shopping experience and also removed the possibility for meaningful social interaction. In our survey, respondents' feelings of higher levels of stress linked with shopping are associated with investing more time in planning their shopping, shopping less frequently (and engaging in some stockpiling) and even transferring the shopping task to another household member. Furthermore, the "panic buying" and stockpiling of certain commodities in the initial phase by some consumers could have been, in part, a psychological response to increased anxiety and a desire to have some control over their lives; it was a means to address general uncertainty and done as an insurance against future supply shortages (Cranfield, 2020). While there is limited evidence of stockpiling of toilet roll in Ireland according to our research, it was one of the products stockpiled across many countries in the initial weeks of the pandemic. This stockpiling behaviour has been linked to the perceived threat of COVID-19 and suggests that toilet paper served as a subjective symbol of safety in some contexts (Garbe et al., 2020). We also see indications of food serving many roles beyond its basic function in terms of nutrition through an increase in cooking from scratch behaviour for example; this could be due to having more time to perform practices that better reflect people's ideals on the role of food within the family environment. While not investigated in our survey, anecdotal evidence from online food-related postings suggests the importance placed on food during this time in terms of social interaction and also in terms of its hedonistic aspects.

The reported changes reflect the different coping strategies adopted by Irish consumers in the face of a changed context, with two distinctive consumer groups identified based on different coping strategies. Differences in these groups are associated with different changes in behaviour from before the lockdown to during the lockdown. It is important to note that many of these changes within the two groups were not apparent in most cases pre-lockdown, highlighting the need for constant market insight generation in this unprecedented time. The importance of this is evident in Lidl's launch of a new rewards app called Lidl Plus (https://www.lidl.ie/lidlplus) in July 2020. While communicating a desire to offer greater value to its customers during these challenging times and also resonating with ideas around safety (contactless) and sustainability (plastic free), this app also provides Lidl with data to generate market insights. It is significant that it is app based rather than a loyalty card, reflecting not only an understanding of the need to minimise risk through its contactless characteristic, but also an understanding of the need to minimise hassle and inconvenience for certain consumer segments during the shopping experience, which is seen as an unpleasant and frustrating experience for many shoppers nowadays. The development of online platforms such as Squid ("Ireland's highest ranking loyalty programme" according to their website $)^{2}$ provides opportunities for smaller businesses to offer more value through rewarding loyalty while also capturing such data.

These findings have implications for both food supply chain actors and PHN. In the short term, stockpiling behaviour has implications for the operations of the supply chain and for pack size and shelf life. As we expect consumers will continue to shop less frequently, and in light of a likely increased focus on value as the economic impact of job losses and furloughs at the household level becomes more apparent, manufacturers could support consumers in this behaviour, without simultaneously increasing waste, by working to extend the shelf life of their products.

While internationally many countries reported a rapid shift from in-person grocery purchases to e-commerce as an objective safety response (e.g. Grashuis et al. [2020] report that the market share of online grocery retailing increased from $3 \%-$ $4 \%$ to $10 \%-15 \%$ during the COVID-19 pandemic in the United States), our research only provides limited evidence of this. This may reflect the availability of online grocery services at the time. Retailers are however rapidly responding to changes in consumer shopping behaviour and attitudes; retailers, for whom e-tailing was not an important element of their strategy to date, are now providing an online shopping or delivery service. While two supermarket chains, Tesco and Supervalu, already had online and home-delivery services, to respond rapidly and in an environment characterised by high levels of uncertainty, other retailers have outsourced such services through engaging in collaborations with companies such as Buymie and Deliveroo. In October 2020, the supermarket chain Dunnes Stores, which has the second largest share of the grocery market in Ireland, entered a partnership with Buymie to offer a same-day home-delivery service to customers from 24 stores in Dublin and Cork, operated via an app ${ }^{3}$. An important element of this service, which addresses consumers' negative attitudes towards shopping, is the availability of a personal

${ }^{2}$ https://www.squidloyalty.ie/.

${ }^{3}$ https://www.irishtimes.com/business/retail-and-services/ dunnes-stores-launch-new-groceries-home-delivery-service-1.4371803. 
shopper who will let customers know if a product is out of stock, suggest alternatives and look for items that a customer cannot find themselves on the app. The two main discounters in Ireland have also partnered with delivery services (Lidl with Buymie and Aldi with Deliveroo), which means that multiple retailers cannot become complacent on price as a result of offering an additional valued service. A strategic decision for retailers is whether to continue to outsource, bring such services in-house or, less likely, to divest themselves of such operations. While online shopping for grocery items is valued now due to consumers' wishes to avoid risk, Grashuis et al. (2020) argue that retailers need to make strategic adjustments in response to the dynamic character of the COVID-19 pandemic and suggest that retailers tailor their offering with regard to the shopping method in response to different rates of new COVID-19 cases. This suggestion is based on their findings from a choice experiment involving US consumers regarding their preferences for different shopping methods (in-store shopping, kerbside collection, home delivery); they found that when the number of COVID-19 cases is increasing, consumers are generally less willing to shop in store; however, when COVID-19 cases are falling, consumer preferences for home delivery, relative to other options, are reduced. In considering the medium to long term, such decision-making should consider the factors identified in previous research as barriers to online shopping which may resurface in the future. For example, Rasty et al. (2020) reported that the most important barriers to trust in online shopping are "privacy risk", "lack of feel-and-touch associated with online purchases", "psychological risk", "social risk" and "feeling that e-vendors are pretending to care about buyers' welfare". While increased shopper experience with such services may reduce or eliminate the perceived risks, the sensory aspects associated with food shopping in particular may become more important again when anxiety levels lower. The design of a virtual store to enhance the hedonic experience of the customer could be a game-changer however. Another decision to be made in the future is whether to provide such services from a store or from a dedicated fulfilment depot within easy access of good road infrastructure. Such developments will have considerable implications for urban planners, who are already re-imagining spaces because of COVID-19-related changes and/or accelerated developments.

The trend towards more planning and preparation from scratch identified in this research reflects an increase in cognitive effort by consumer with regard to food - they spend more time and effort thinking about food, about where it comes from and the activities undertaken by themselves and others prior to consumption. From a PHN perspective, this provides an opportunity for new healthy habits to form; it represents a "teachable moment". However, anecdotal evidence also highlights a cause for concern around the health consequences linked to the types of foods that consumers bought more of (e.g. comfort foods, old favourites and indulgent snacks). Consumers were thought to use these foods as a source of comfort during the lockdown, but the risk is that these may become embedded in the routines and practices of the household in the longer term. While consumers may be familiar with voluntary, self-imposed restrictions associated with campaigns such as Go Sober for October ${ }^{4}$ (a campaign run by MacMillan Cancer Support in the UK) or Veganuary (a campaign run by a non-for-profit organisation to promote a vegan diet $)^{5}$, public health messaging in the current context needs to be different. Positive framing is essential in an environment in which consumers are coping with frustrations and difficulties associated with imposed restrictions and messaging needs to be constructed in a positive, non-sacrificing way. The findings of Shen \& Dillard (2007) who reported that advantage framing, where the benefits of a change are highlighted, yields stronger positive emotions compared to disadvantage framing which produces stronger negative emotions, are relevant in this context. It will be particularly important to ensure that returning to/developing new healthy habits are not made difficult for the more "restless restrictors" group identified in this research.

The COVID-19 context has had a positive impact on demand for well-recognised brands. Companies such as Nestlé, Kraft and Heinz have reported a very strong 2020 sales performance (particularly in Q1 2020). While some of this may be due to stockpiling behaviours, consumer feelings of anxiety and food safety concerns may have resulted in a move by some towards well-established brands. Trust and confidence associated with such brands may have offered reassurance. Importantly, this may be a feature of food shopping behaviour for some time to come. Research by Mehrolia et al. (2020) on consumer behaviour during COVID-19 in India highlights the importance of cues to action in relation to behaviour and they commend online food delivery providers for undertaking marketing campaigns to reassure consumers that they were following all safety measures and prioritising safety at all stages. Such reassurances are also likely to be valuable for branded goods manufacturers in providing cues for action by their consumers.

Price did not seem to be an important factor influencing behaviour within this sample at the time of the survey. However, as both the domestic and international economies slow down, due to reductions in economic activity, there will be an increasing focus on value among many consumers and this will, most likely, become an increasingly important factor in food choice behaviour. There is already evidence of the emergence of price wars in the UK with a headline "Sainsburys

\footnotetext{
${ }^{4}$ https://www.gosober.org.uk/.
}

${ }^{5} \mathrm{https}: / /$ veganuary.com/. 
wades into price war with round of 300 price cuts" in the trade magazine the Grocer on 10 October $2020 .^{6}$ They reduced prices by up to $30 \%$ on what they called "family favourites" which include fresh meat and fish, frozen products and dry goods. The magazine reports, "This price offensive is a further sign of looming price war between the major supermarkets. The food retail industry is taking steps to increase footfall and lure customers in with reduced prices, with Asda and Tesco all launching price cutting initiatives".

This research clearly shows how a change in the external environment (in this case the lockdown and everything this involves) influences consumer food-related practices and routines. Furthermore, it highlights distinctive impacts on different consumer segments. This provides both a need and an opportunity to tailor commercial and PHN initiatives accordingly. Additionally, it brings into clear focus the need to reshape retail service offerings, both in-store, through store atmospherics, and online. In the future, we expect to witness the emergence of segments that visit food retail stores as a leisure activity to consider new innovative foods that they might add to their cooking repertoire, while using online services as their primary route to acquire food. Within this context (increasing use of online services), retailers need to consider sustainability (e.g. design of the delivery model routes and packaging), convenience (not only in ordering and delivery but in bundling of product offerings, e.g. suggestions of combinations of products that create meal solutions to minimise the cognitive effort around meal planning), value (could be offered through offering raw ingredient meal boxes based on household sizes and preference), transparency and health. Manufacturers will need to pay attention to the protection of their brand position and be prepared for a heightened consumer focus on price. Clear communication and meaningful value propositions will be needed to protect the brand from downward price pressures.

While this research provides interesting insights into consumer behaviour, the results should be interpreted in light of the profile of the respondents to the survey and the questions asked. It should also be noted that this survey took place during the first lockdown. It is likely that there are many differences between the first, second and third lockdown in terms of behavioural and emotional responses. Our sample has a relatively high proportion of highly educated people compared to the general population. This may skew our results slightly and reflect our observation regarding the limited impact of price discussed above (possibly because

\footnotetext{
${ }^{6} \mathrm{https}$ ://www.thegrocer.co.uk/prices-and-promotions/ sainsburys-wades-into-price-war-with-round-of-300-pricecuts $/ 649130$.article\#: : :text=Sainsbury's\%20has\%20become $\% 20$ the $\% 2$ latest,frozen $\% 20$ lines $\% 20$ and $\% 20$ dry $\% 20$ grocery.
}

people are more likely to work in jobs that allowed them to continue to work from home). Nonetheless, research from the Netherlands indicates that such groups are more likely than others to change their behaviour in some aspects. Poelman et al. (2020) report that those with higher education levels are more likely to react to COVID-19 restrictions with unhealthy behaviours, including tending to eat more unhealthily and buy more sweets and alcoholic beverages than those with lower education levels, indicating a need to pay particular attention to such groups.

The questions asked of consumers were related to their primary food behaviours and attitudes. Thus, for example, in relation to shopping, it focused on the main grocery shop. It does not capture behaviour whereby consumers buy speciality and/or fresh food locally through speciality retailers (including butchers and greengrocers) and purchase directly from food and beverage producers via short food supply chain (e.g. buying craft beers online). Thus, the results are unlikely to reflect shifts in behaviour amongst such distribution channels. There is anecdotal evidence of an increased ethos of supporting local, which results in an expectation that such channels are increasing in importance. Furthermore, it does not consider individual food categories for which consumers may have different attitudes and thus behaviours, for example, fresh food versus staples, pork versus beef.

All responses are self-reported. Thus, while consumers self-report that they do more cooking from scratch, there is anecdotal evidence that while household meal repertoires have been extended, there is a considerable element of "meal component assembly" as opposed to cooking that requires the development of a high level of skills. Consequently, public health messaging should be conscious that food literacy skills may not have increased to the extent that may be suggested by this research. Nonetheless, with a growing concern for value, there may be an opportunity to provide consumers with sufficient skills that enable them to utilise healthy cheaper food alternatives, for example, cheaper cuts of meat.

This paper does not consider the implications of significant changes in decision-making by other actors in the food supply chain that have arisen as a result of COVID-19 restrictions on the food supply chain or PHN. Some of these are quite significant and will have long-term implications for supply chain function, for example, issues relating to the availability of labour and worker welfare. Significant changes in and implications for the food service market and out-of-home consumption and food-to-go are not addressed.

\section{Acknowledgements}

This study is part of an international study involving 38 countries worldwide. It was initiated by the Corona Cooking 
Study Group which comprised Lauranna Teunissen, Isabelle Cuykx, Paulien Decorte, Sara Pabian, Kathleen Van Royen and Charlotte De Backer from the University of Antwerp.

\section{References}

Becdach, C., Brown, B., Halbardier, F., Henstorf, B. and Murphy, R. 2020. "Rapidly Forecasting Demand and Adapting Commercial Plans in a Pandemic". April, McKinsey \& Co. Available online: https://www.mckinsey.com/industries/consumer-packagedgoods/our-insights/rapidly-forecasting-demand-and-adaptingcommercial-plans-in-a-pandemic [Accessed 15 November 2020].

Cranfield, J.A. 2020. Framing consumer food demand responses in a viral pandemic. Canadian Journal of Agricultural Economics/ Revue Canadienne D'agroeconomie 68: 151-156.

De Backer, C.J.S., Teunissen, L., Cuykx, I., Decorte, P., Pabian, S., Gerritsen, S., Matthys, C., Al Sabbah, H. and Van Royen, K. 2021. An evaluation of the COVID-19 pandemic and social distancing policies in relation to planning, selecting, and preparing healthy meals: an observational study in 38 countries worldwide. Frontiers in Nutrition 7: 375.

Devine, C., Connors, M., Bisogni, C. and Sobal, J. 1998. Life course influences on fruit and vegetable trajectories: a qualitative analysis of food choices. Journal of Nutrition Education 31: 361-370.

Di Renzo, L., Gualtieri, P., Pivari, F., Soldati, L., Attinà, A., Cinelli, G., Leggeri, C., Caparello, G., Barrea, L., Scerbo, F., Esposito, E. and De Lorenzo, A. 2020. Eating habits and lifestyle changes during COVID-19 lockdown: an Italian survey. Journal of Translational Medicine 18: 229.

Garbe L., Rau R. and Toppe T. 2020. Influence of perceived threat of Covid-19 and HEXACO personality traits on toilet paper stockpiling. PLoS One 15: e0234232.

Grashuis, J., Skevas, T. and Segovia, M.S. 2020. Grocery shopping preferences during the COVID-19 pandemic. Sustainability 12: 5369.

Kessler, R.C., Andrews, G., Colpe, L.J., Hiripi, E., Mroczek, D.K., Normand, S.L.T., Walters, E.E. and Zaslavsky, A.M. 2002. Short screening scales to monitor population prevalences and trends in non-specific psychological distress. Psychological Medicine 32: 959-976.

Lagunaa, L., Fiszmana, S., Puerta, P., Chaya, C. and Tárrega, A. 2020. The impact of COVID-19 lockdown on food priorities. Results from a preliminary study using social media and an online survey with Spanish consumers. Food Quality and Preference 86: 104028.

McCarthy, M., Collins, A., Flarherty, S.J. and McCarthy, S. 2017. Healthy eating habit: a role for goals, identity, and self-control? Psychology \& Marketing 34: 772-785.

Poelman, M.P., Gillebaart, M., Schlinkert, C., Dijkstra, S.C., Derksen, E., Mensink, F., Hermans, R.C.J., Aardening, P., de Ridder, D. and de Vet, E. 2020. Eating behavior and food purchases during the COVID-19 lockdown: a cross-sectional study among adults in the Netherlands. Appetite 157: 105002.

Rasty, F., Mirghafoori, S.H., Ardakani, S.S. and Ajdari, P. 2020. Trust barriers to online shopping: investigating and prioritizing trust barriers in an intuitionistic fuzzy environment. International Journal of Consumer Studies 157: 105002.

Robinson, E., Boyland, E., Chisholm, A., Harrold J., Maloney, N.G., Marty, L., Mead, B.R., Noonan, R. and Hardman, C.A. 2021. Obesity, eating behavior and physical activity during COVID-19 lockdown: a study of UK adults. Appetite 156: 104853.

Shen L. and Dillard J.P. 2007. The influence of behavioral inhibition/ approach systems and message framing on the processing of persuasive health messages. Communication Research 34: 433-467.

Van't Riet, J., Sijtsema, S.J., Dagevos, H. and de Bruijn, G.J. 2011. The importance of habits in eating behaviour: an overview and recommendations for future research. Appetite 57: 585-596.

Verplanken, B. and Aarts, H. 1999. Habit, attitude, and planned behavior: is habit an empty construct or an interesting case of goal-directed automaticity? European Review of Social Psychology 10: 101-134.

Verplanken, B. and Wood, W. 2006. Interventions to break and create consumer habits. Journal of Public Policy \& Marketing 25 90-103. 